\title{
O BEM COMUM COMO ELO ENTRE ÉTICA E POLÍTICA A PARTIR DE ARISTÓTELES E HANNAH ARENDT: UM DEBATE ATUAL E NECESSÁRIO
}

João Gabriel Moraes de Souza ${ }^{1}$

Resumo: O artigo tem o objetivo de debater o pensamento político de Hannah Arendt e sua interpretação da política no século XX, onde se destaca a retomada por parte da autora de um dos principais expoentes sobre tal tema, que foi o Filósofo da antiguidade clássica: Aristóteles, ele compreendia a ética indissociável da política, através do conceito de bem comum. Assim, o texto que se segue, busca levantar algumas questões sobre ética e política.

Palavras-chave: Bem comum. Ética. Política.

\section{THE COMMON GOOD AS A BIND BETWEEN ETHICS AND POLITICS FROM ARISTOTLE AND HANNAH ARENDT: A CURRENT AND NECESSARY DEBATE}

\begin{abstract}
The article aims to debate the political thought of Hannah Arendt and her interpretation of politics in the 20th century, which highlights the resumption by the author of one of the main exponents on this theme, who was the Philosopher of classical antiquity: Aristotle, he understood the inseparable ethics of politics, through the concept of the common good. Thus, the text that follows seeks to raise some questions about ethics and politics.
\end{abstract}

Keywords: Very common. Ethic. Policy.

${ }^{1} \mathrm{O}$ autor possui graduação em História pela Universidade Federal do Pará UFPA (LICENCIATURA BACHARELADO) (2014) e mestrado em CIÊNCIAS DA RELIGIÃO pela Universidade do Estado do Pará UEPA (2017). Atualmente cursa Filosofia na Universidade Federal do Pará UFPA 2018 (LICENCIATURA / BACHARELADO) e mestrando do Programa de Pós Graduação em Filosofia da UFPA.Tem experiência na área de História, com ênfase em História do Brasil República, História Política, casamento, secularização e instituições religiosas, além de amplo conhecimento em Teologia, Filosofia das religiões, ética, política e Filosofia Geral. Currículo Lattes: http://lattes.cnpq.br/1014155202400391. 


\section{Introdução}

Esse artigo tem por objetivo destacar o pensamento político de Hannah Arendt e a proposta de levantar algumas questões importantes desse aspecto fundamental do pensamento da autora em questão, sem ter a pretensão de esgotar o assunto propõe-se refletir na atualidade das reflexões da filósofa. É importante ressaltar a rejeição da própria autora às credenciais de filósofa embora tenha dado ampla contribuição ao campo filosófico, gostava de ser vista como uma teórica política. Como observa-se em algumas de suas obras, para sustentar sua análise política, a autora vai apoiar-se no pensamento aristotélico e na polis grega principalmente no que concerne a não separação da ética da política, no que diz respeito as esferas pública e privada sendo o conceito que melhor representa a união entre ética e política: o bem comum.

Antes de discorrer sobre como autora vai interpretar esse pensamento aristotélico, no mundo contemporâneo faz-se necessário metodologicamente, esclarecer alguns pontos da filosofia política de Aristóteles, para justamente se compreender melhor o pensamento de Arendt. Deste modo a breve análise a se tecer sobre ética e política, no pensamento do filósofo Estagirita, gira em torno das obras Ética a Nicômaco e Política, buscando sobretudo apontar o erro de muitos estudiosos em separar a ética da política afirmando erroneamente que o próprio Aristóteles teria feito essa divisão nas suas obras: Ética a Nicômaco e Política. Para esses estudiosos, Aristóteles teria sido o primeiro filósofo a distinguir a ética da política, centrada a primeira, na ação voluntária e moral do indivíduo enquanto tal, e a segunda, nas vinculações deste com a comunidade.

\section{Aristóteles, Ética e Política}

Para defender a não separação entre ética e política em Aristóteles, Patrício Tierno, aponta que existe uma necessidade de refletir essa temática como os antigos investigavam (TIERNO, 2019); como Hannah Arendt sustenta também, deve-se destacar que um dos principais autores da modernidade que fazem a divisão entre os conceitos seria Maquiavel²,

\footnotetext{
${ }^{2}$ Embora não aprofundemos esse debate entre Aristóteles e Maquiavel em nosso texto, é necessário esclarecer que o florentino é um importante autor para esse debate e de certa forma ele é um divisor de águas entre o antigo e o moderno, mas acaba elevando a política em detrimento de qualquer viés moral, pois vemos na sua obra que um príncipe não deve se preocupar com os meios para manter o estado para os súditos; assim no capítulo VII do príncipe, Bignotto aponta que Maquiavel segue o caminho que fora traçado no inicio da obra, onde ele pretende elucidar um caso limite da conquista, a saber, aquele de um príncipe que recorre a meios antiéticos para chegar ao poder. É de se notar que essa via que as traduções brasileiras consagraram como a "via criminosa", possui a mesma característica dos principados civis, ou seja, não depende nem da virtú, nem da fortuna dos que a
} 
proporcionando um debate que possa confirmar a hipótese de que não se pode haver uma divisão entre ética e política no pensamento aristotélico, destacando o conceito de bem comum, primordial para se entender a não dissociação desses termos.

Assim, esse caminho de interpretação pode ser justificado pelas últimas ocorrências observadas no cenário político brasileiro e mundial, que acabam mostrando uma separação entre ética e política, revelando um desprezo aos preceitos morais na disputa pelo domínio do Estado; acontecendo de certa forma o predomínio do que chama de visão moderna acerca da ação política, que tem Maquiavel como seu principal expoente.

Pode-se dizer que existe na modernidade um renascimento do debate entre ética e política, onde parte desse ressurgimento se dá principalmente por causa das obras de Hobbes e Maquiavel que trazem de certa forma um viés cientifico objetivo para a política. Maquiavel, por exemplo, mostra em sua obra que o Estado seria algo natural, tratando o termo como um fato, assim sendo acaba não dizendo nada sobre a natureza do Estado, seguindo um modelo muito descritivo já que as bases do método de Maquiavel seriam a História e a Antropologia.

Com objetivo de investigar essa questão que se tornou bastante comum e aceita, principalmente graças aos novos rumos tomados pela reflexão na modernidade que, privilegiam a distinção entre os objetivos sociais que orientam a ética e a política e embora essa separação seja evidente entre os modernos por causa do pensamento político de Maquiavel, sendo que nessa seção destaca-se o pensamento de Aristóteles, em razão de certas interpretações que são feitas da chamada parte prática de sua filosofia, com a intenção de compreender como Arendt vai retomar esse pensamento aristotélico, no mundo contemporâneo.

Hobbes por sua vez, busca uma teoria geral da natureza, mostrando primeiramente uma cosmologia para depois falar de uma teoria política o que de certa forma acontece no Timeu de Platão (PLATÃO, 1956). Pode-se dizer que Hobbes é menos radical que Maquiavel em suas teorias políticas já que a problemática dele está em assegurar a obediência e não em aconselhar o governo como o Florentino (HOBBES, 1974).

Para desenvolver a relação entre ética e política em Aristóteles, e assim melhor compreender o pensamento de Hannah Arendt, deve-se ter como apoio sobretudo a ideia de bem comum, que Aristóteles constrói como destaca-se acima, pois para ele a política deve

escolhem. Para saber mais sobre o assunto ver: BIGNOTTO, Newton. As fronteiras da ética: Maquiavel. In: NOVAES, Adauto (org.). São Paulo: Companhia das Letras, 2007. 
beneficiar a todos em detrimento do privado, ou melhor, dizendo do individual, pois o homem nasceu para a cidadania (ARISTÓTELES, 1987). Segundo Aristóteles (1987), o cidadão deve ter um comportamento político que vise o bem comum de todos ou seja, cada um deve ter um comportamento necessário de acordo com os padrões sociais, sendo que no aspecto privado o que prevalece é a vontade do indivíduo, mostrando assim que o comportamento ético só pode ser vivenciado publicamente e não privadamente.

A partir disso, pode- se fazer a seguinte reflexão: Por que existe o problema moral? Cuja resposta segundo a ética aristotélica nos dirá que sempre haverá um conflito entre o indivíduo e a sociedade e por isso um ser humano é aquele que aprende a conviver com os outros seres humanos, algo muito presente na filosofia de Hannah Arendt, no que tange o contexto que a autora manteve sua pesquisa, principalmente a Segunda Guerra Mundial, o pós-guerra e a questão dos direitos humanos.

É somente então que a voz do dever sucedendo ao impulso físico e o direito ao apetite, o homem, que até então só havia considerado a si mesmo, vê-se forçado a agir segundo outros princípios e a consultar a razão, antes de escutar suas inclinações. Portanto faz-se necessária uma relação sobre a questão da natureza animal humana, em Aristóteles, para tentar compreender melhor a ideia de bem comum que uniria ética e política e compreender que Arendt está inserida dentro de todo este debate.

Para seguir ao fim dessa seção, sobre o pensamento de Aristóteles e então compreender porque a autora retoma isso na contemporaneidade é importante destacar também a ideia de virtude, na Ética a Nicômaco (ARISTÓTELES, 1987). Assim a virtude seria experimentada somente em sociedade, já que não podemos falar de justiça e injustiça na natureza; por isso reafirmamos segundo o pensamento de Aristóteles sobre a necessidade das leis, mostrando que as leis não oprimem, pois elas seriam na verdade aquilo que obriga o homem, pois somos por natureza individuais, devemos aprender a conviver. Assim as leis seriam o critério comum da ação, por isso deve-se rejeitar a ideia de uma lei individual, sendo que em tese a lei deveria controlar nossa agressividade.

Não por acaso Aristóteles diz na Política no Livro III Capítulo IV que O bom cidadão é aquele que presta bons serviços a sua cidade, e essa cidade pode ser ruim em principio. Em uma cidade constitucional, os bons cidadãos sabem governar e obedecer. $\mathrm{O}$ homem bom, portanto, é aquele bem preparado para governar; sendo que o cidadão em uma cidade constitucional aprende a governar pela obediência as ordens, já que a cidadania em uma cidade para Aristóteles seria um treinamento moral (ARISTÓTELES, 1987). 
Por isso Aristóteles fala em bem humano e não individual, porque o indivíduo seria um animal, que ficaria limitado apenas a esfera do entendimento e o ser humano seria o ideal, e quem cuida do ideal é a razão que visaria o bem comum na política para Aristóteles, pois o bem comum seria algo que traria benefícios a todos, em prejuízo ao interesse privado do indivíduo.

\section{Hannah Arendt e seu pensamento político}

Em Origens do Totalitarismo Hannah Arendt mostra o impacto desse modelo na destruição do campo político, sendo que essa destruição acaba levando a perda de nossos direitos já que em uma sociedade moldada por um regime fascista, por exemplo, há uma negação da política, onde a autora mostra que só podemos reconstruir nossa sociedade através da política; e por conseguinte, só iremos restabelecer a dignidade humana através da reconstrução do ambiente político, pois para a filosofa esse campo está inteiramente ligado com a ética e com o respeito ao outro (ARENDT, 2012).

É de suma importância compreender que a filósofa aponta que a saída da vida política através da dominação total pelo terror com perseguições e a retirada da espontaneidade dos indivíduos é uma estratégia dos regimes fascistas, para enfraquecer o espaço político que seria essencial para o homem, como ensinou Aristóteles na antiguidade e a pensadora em questão, retomou na contemporaneidade.

Nesse trecho da sua obra, é famosa a sua concepção de sociedade como uma cebola, onde existe o líder no centro e os outros níveis se localizam nas demais camadas da sociedade, existindo assim um constante patrulhamento e vigilância, onde eu posso denunciar o outro, ou ser denunciado de atuar contra o governo (ARENDT, 2012). Portanto à uma destruição das condições para uma ação política dos indivíduos, havendo um domínio público que nega a pluralidade, liberdade e ação.

Para exemplificar todo esse esvaziamento da política na contemporaneidade Arendt mostra que no regime nazista existe um processo de desumanização das pessoas, que perdem a sua pátria e são levadas a se considerarem como nada, enxergando suas vidas como totalmente supérfluas como acontecia nos campos de concentração judeus (ARENDT, 2012).

Esse tipo de proceder no mundo contemporâneo, segundo Hannah Arendt, está ligado a uma visão teleológica da História, que visa alcançar um fim determinado, através de meios às vezes antiéticos mesmo que para se alcançar tais fins, deva se sacrificar vidas como aconteceu no campo de concentração nazista, sendo que de acordo com ela esse ambiente de 
terror acaba por destruir a política e consequentemente a liberdade dos indivíduos, pois como viu-se não há como dissociar a ética da política, segundo a concepção de Arendt, que corrobora com o pensamento de Aristóteles.

Com base em tudo o que foi exposto até o momento, pode-se dizer que Hannah Arendt demonstra que há uma negação da política, sendo algo preocupante, já que atualmente o ambiente político não serviria muito para a resolução de problemas, sejam eles individuais ou da sociedade, pois há uma total descrença no campo político, o que acaba proporcionando abertura para tendências fascistas com um proposital esvaziamento do campo político (ARENDT, 2012).

Com o neoliberalismo por exemplo, como modelo governamental de vários países na atualidade, pode-se ressaltar que há uma retração do mundo político e o crescimento das individualidades e da esfera privada, visando o lucro e o empreendedorismo com um projeto de meritocracia, individualismo e egocentrismo, o que acaba soando diferente do ideal de democracia com o qual o mundo ocidental acostumou-se, os ideais de: igualdade, liberdade e fraternidade.

Sendo assim, podemos apontar uma contradição dentro do próprio neoliberalismo, pois esse modelo governamental prezaria pela liberdade do indivíduo, que de certa forma guiaria seu plano de vida, já que podemos perceber nitidamente, que o neoliberalismo moderno prega a liberdade e nega as diferenças, (GARGARELA, 2009). Ou seja, há uma contradição nas próprias bases do liberalismo, pois esse modelo surge ao longo da História humana como um movimento que combateu o autoritarismo e hoje aparece como projeto de governos autoritários e com forte tendência fascista.

Vale destacar que na sua obra Origens do Totalitarismo, Arendt mostra o impacto desse tipo de regime e por consequência uma destruição do ambiente político, havendo uma negação da política que acaba levando a perda de direitos individuais, pois vivemos uma demonização do debate político, que deve ser reconstruída em nossa sociedade, segundo a filosofa (ARENDT, 2012). Assim só podemos retomar a dignidade humana, através da reconstrução política, pois para Hannah Arendt, o campo político está inteiramente ligado, com a ética e com o respeito ao outro, ou seja, estaria nas mesmas bases, daquilo que Aristóteles pensou para a política ligada a ética através do bem comum.

Depois dessa visão geral de Origens do totalitarismo é importante fazer uma relação com outra obra relevante para a compreensão do pensamento político de Hannah Arendt que seria: Eichman em Jerusalém. Sendo que algo essencial nesse texto da autora e que nos 
interessa para o debate até aqui apresentado, é a questão da tolerância silenciosa, que seria algo que acabaria por levar as massas a não agir politicamente pois não teriam segundo a autora consciência de classe e nem consciência do seu poder, para o bem comum (ARENDT, 1999). Sendo que no modelo democrático, o que comanda seria a vontade da maioria, ou seja, as massas sendo que a constituição nesse modelo seria o que garantiria os direitos fundamentais.

Já em A condição humana Arendt critica os intelectuais e filósofos, que acabam focando muito em teorias e esquecem o campo político sendo que alguns desses intelectuais segundo Hannah Arendt, seriam lenientes ao regime nazista na Alemanha ${ }^{3}$. Outra crítica importante feita pela filósofa, seria ao platonismo e seu viés antidemocrático, com a tese dos reis filósofos desenvolvida por Platão ${ }^{4}$; sendo que na verdade, segundo a autora, isso acaba revelando o desprezo pelo povo, visto como um elemento ineficaz de atuar politicamente onde Arendt acaba por destacar, que o filósofo grego de certa forma é influenciado pela morte de Sócrates, em interpretar as massas como incapaz de atuar na política.

É importante pontuar que para Arendt, a esfera política não pode ser apenas pensada ou teorizada, mas acima de tudo deve ser vivido na prática. Não devemos deixar de destacar que na antiguidade havia uma recusa muito grande ao modelo democrático onde o povo possa participar e decidir. Nietzsche por exemplo, critica a ideia de democracia, já que segundo o pensamento do filósofo isso apequenaria o homem pois para o autor existe uma ideia que todos são iguais segundo a concepção cristã, contudo para o pensador, não existe tal igualdade, mas apenas enquadraria homens excepcionais e medíocres no mesmo patamar, proporcionando assim uma ideia de rebanho (NIETZCHE, 1991).

Para continuar essa reflexão, destaca-se a existência de muitos desacordos em nossa sociedade, seja no campo moral, cultural ou religioso sendo que esses conflitos devem ganhar eco no campo político segundo Arendt e no momento que não se exalta a política acaba-se por exaltar a tirania, já que o espaço da política é o espaço da pluralidade e não de uma única visão. Sendo assim, para a autora não é possível ficar apenas na teoria, pois a filosofia deveria ter um engajamento ultrapassando os muros da simples reflexão filosófica,

\footnotetext{
${ }^{3}$ É famoso o caso de Martin Heidegger e seu envolvimento com o partido nazista. Isso não quer dizer que afirmamos aqui que a crítica feita por Hannah Arendt seja a Heidegger, mas apenas um exemplo, que estaria dentro do contexto histórico que a autora analisa; mais detalhes sobre o assunto VER Vida e Obra de Heidegger IN: HEIDEGGER, Martin. Conferencia e escritos filosóficos; tradução e notas de Ernildo Stein. São Paulo: Abril Cultural, 1979. (Os pensadores), (Pg 6-11).

${ }^{4}$ Podemos ver isso, na tese dois reis filósofos e a incapacidade do povo para o governo, que está na parte central da República de Platão, mais precisamente no LIVRO VI, onde Platão através de Sócrates fornece a imagem do navio para a defesa dos filósofos como os mais capacitados para o governo da cidade.
} 
refletindo assim em uma participação maior na vida política, sendo isso fundamental e segundo a pensadora, a essência da vida humana e sua realização (ARENDT, 2010).

Já quando se trata da questão da esfera privada e pública, no campo político, a autora defende a total distinção dessas duas esferas, assim como Aristóteles (ARENDT, 2010). Contudo deve-se destacar que Arendt nessa parte do seu pensamento sofre duras críticas por parte do movimento feminista, que aponta uma preocupação em relação ao pensamento de Hannah Arendt já que segundo as feministas, quem fica no espaço privado não teria representação no público, pois historicamente as mulheres foram destinadas ao doméstico, sendo privadas de muitos direitos. A partir disso, o movimento feminista ataca a filósofa pois quem cuidaria das coisas domésticas para a ação política?

Mas apesar de todos esses problemas envolvendo o pensamento de Arendt, pode-se afirmar que a pólis grega para a autora é o exemplo maior a seguir, pois era na antiguidade que o homem discutia política em praça pública, sendo que na modernidade isso de certa forma se perde. Para frisar essa sua tese mostrada no parágrafo anterior, a filósofa vai falar que o ser humano tem dois tipos de nascimento, sendo que o primeiro nascimento seria alcançado por todos os homens, já o segundo nascimento, nem todos alcançariam, pois seria aquele que o homem atinge pela sua entrada na vida pública, ou seja, na política, pois a política é o espaço de realização da ação humana (ARENDT, 2010).

Assim na modernidade há um esquecimento da esfera política, segundo Arendt como havia na antiguidade, onde os cidadãos faziam política em praça pública; pois a filosofa destaca certa preocupação no mundo contemporâneo, com o fazer em detrimento do agir, pois como as pessoas estão muito tempo fazendo trabalhos domésticos ou fabricando coisas, (animal laborans, homo faber) o fazer acaba ganhando maior importância em detrimento do agir (agir político: ação, práxis) principalmente em uma sociedade capitalista, pois na modernidade há um esvaziamento da política; sendo que na Grécia antiga os homens tinham tempo livre para essa atividade.

\section{Considerações finais}

Em uma época onde os debates são efusivos em torno da ética e política, há não somente uma necessidade de se discutir o assunto, mas de suscitar algumas questões importantes sobre o tema, pois esse sempre foi o trabalho da Filosofia que vai além do esforço de encontrar respostas, mas acima de tudo, busca levantar questões que possam levar o homem a compreender sua condição e seu lugar na existência. Sendo assim, esse foi o 
motivo de se trazer à luz um pouco do pensamento de Hannah Arendt e sua interpretação da política no século XX, com a retomada do pensamento de Aristóteles que compreendia a ética indissociável da política.

Desse modo procurou-se mostrar a importância do pensamento ético político de Aristóteles inicialmente, para melhor compreendermos a teoria de Arendt pois como mostrou Patrício Tierno, há uma necessidade de se pensar nessa temática como os antigos investigavam. Não por acaso Arendt busca referência para suas reflexões políticas do mundo contemporâneo na polis grega, principalmente na filosofia aristotélica, sendo que todas as questões abordadas no texto são extremamente necessárias e urgentes para a área da Filosofia atualmente no que concerne o campo político na modernidade que busca compreender a ética separada da política.

Hannah Arendt, atenta a essa tendência, retoma Aristóteles e demonstra que há uma retração do debate político já que como é divulgado nos dias atuais, a política não serviria para resolver conflitos e demandas, sejam eles individuais ou da sociedade, havendo uma demonização da política como um ambiente exclusivo de corrupção, diminuindo sua importância como ferramenta de diálogo, resultando em uma total descrença no ambiente da política, o que acarreta na abertura de espaço para o fascismo.

\section{REFERÊNCIAS BIBLIOGRÁFICAS}

ARENDT, Hannah. Eichmann em Jerusalém. Um relato sobre a banalidade do mal. São Paulo: Companhia das Letras, 1999.

ARENDT, Hannah. A Condição Humana. Rio de Janeiro: Forense Universitária, 2010. (Apresentação à nova edição brasileira: Adriano Corrêa; Capítulo I).

ARENDT, Hannah. Origens do totalitarismo; tradução Roberto Raposo. — São Paulo: Companhia das Letras, 2012.

ARISTÓTELES. Ética a Nicômaco. Edição os pensadores. Tradução de Leonel Vallando e Gerd Bornheim da versão inglesa de W. A. Pickard - Cambridge -São Paulo: Nova Cultural, 1987.

ARISTÓTELES. Política. Brasília: Universidade de Brasília, 1988.

BIGNOTTO, Newton. As fronteiras da ética: Maquiavel. In: NOVAES, Adauto (org.). São Paulo: Companhia das Letras, 2007. 
GARGARELA, Roberto. As teorias da justiça depois de Rawls: Um breve manual de filosofia política. São Paulo, Martins Fontes; 2008.

HEIDEGGER, Martin. Conferência e escritos filosóficos. tradução e notas de Ernildo Stein. São Paulo: Abril Cultural, 1979. (Os pensadores).

HOBBES, T. Leviatã. São Paulo: Abril Cultural, 1974. (Coleção Os Pensadores).

MAQUIAVEL, N. O Príncipe. Tradução de Pietro Nassetti. - São Paulo, SP: Martin Claret, 2007.

NIETZCHE, Friedrich Wilhelm. Seleção de textos de Gerard Lebrum. São Paulo: Nova Cultural. - (Os pensadores).

NOVAES, Adauto. Ética vários autores. Organização: Adauto Novaes. - São Paulo: Companhia das Letras, 2007.

PLATÃO. Timeu - Crítias. Trad. Carlos Alberto Nunes; organização Benedito Nunes \& Victor Sales Pinheiro; texto grego John Burnet. - 4 ed. ver. e bilíngue. - Belém: ed.ufpa, 2018.

TIERNO, Patricio. Teoria política clássica: ramificações de Grécia e Roma. IN: LUA NOVA, Revista de Cultura e Política. São Paulo. 2019. №109.

Artigo recebido em: $30 / 10 / 20$

Artigo aprovado em: $13 / 12 / 20$ 